\title{
Physiological Health Criteria for Pyrethriod Insecticide: A Pre-test Study with Guinea Pigs
}

\author{
Felicia Ngozi Okoh ${ }^{1, *}$, Oliver Onyemaeze Odikamnoro², Joy Ihuoma Nzei $^{3}$, Ikem Chris Okoye ${ }^{3}$, \\ Fabian Chukwuzubelu Okafor ${ }^{3}$
}

${ }^{1}$ Department of Biological Sciences, Evangel University Akaeze, Abakaliki, Nigeria

${ }^{2}$ Department of Applied Biology, Ebonyi State University Abakaliki, Abakaliki, Nigeria

${ }^{3}$ Department of Zoology and Environmental Biology, University of Nigeria, Enugu, Nigeria

Email address:

liciokoh@yahoo.com (F. N. Okoh)

${ }^{*}$ Corresponding author

\section{To cite this article:}

Felicia Ngozi Okoh, Oliver Onyemaeze Odikamnoro, Joy Ihuoma Nzei, Ikem Chris Okoye, Fabian Chukwuzubelu Okafor. Physiological Health Criteria for Pyrethriod Insecticide: A Pre-test Study with Guinea Pigs. American Journal of Life Sciences.

Vol. 5, No. 4, 2017, pp. 97-102. doi: 10.11648/j.ajls.20170504.11

Received: May 6, 2017; Accepted: May 18, 2017; Published: July 31, 2017

\begin{abstract}
A study of the use of lambdacyhalothrin (pyrethroid insecticide) treated curtains, mats and blankets as an alternative strategy to insecticide treated bed net for malaria control, was undertaken from 2003 to 2004 in Oruku - a suburban community in Nkanu East Local Government, very near Enugu in Enugu state of Nigeria. Prior to the village study, a pre-test study (safety testing) was done using Guinea pigs from January 2003 to April 2003. It was carried out inside zoological garden University of Nigeria, Nsukka. The objective of the pre-test study was to ascertain the effect of Lambdacyhalothrin on physiology of Guinea pigs before using it in human habitation (Guinea pig has physiology akin to human). The Guinea pigs were maintained in animal cages and acclimatized for four weeks before the introduction of the insecticide. Effect of the insecticide on vital physiological parameters of the Guinea pigs were measured weekly for 15 weeks. The data were analyzed using chi-square, ratio (fscore), correlation coefficient ' $r$ ' and coefficient of determination ( $r{ }^{2}$ ). Result showed that Lambdacyhalothrin at $0.001 \mathrm{mg} / 1$ to $0.050 \mathrm{mg} / 1$ concentrations were well tolerated by the guinea pigs and was thought to be safe for use in human environment/habitation with no disruption of physiological activities.
\end{abstract}

Keywords: Guinea Pig, Pyrethriod Insecticide, Physiological Similarities, Malaria Control

\section{Introduction}

The Historical connection between mosquito control and reduction in malaria prevalence is undoubted and so various control studies are designed to find the best control measures. Such studies as vector control methods which remain the most generally effective measure to prevent malaria transmission, example: use of Integrated Vector Management (IVM), Insecticide Treated Materials (ITM) and Indoor Residual Spraying (IRS) [1, 18]. These methods have been reported to be effective in reducing mosquito-man contact, hence reducing the human biting rates by a vector species [16] and ultimately transmission of malaria. This novel method however have some limitations: Integrated Vector Management has not been widely adopted [8]; Insecticide
Treated Nets have limited life span as the insecticide is lost during washing and in exposure to bright sunlight [6]; in recent years, the use of Indoor Residual Spraying has declined. This is due in part to lack of government commitment and financing to sustain these efforts over the long term and to concerns about insecticide resistance and community acceptance and for fear of harmful effect of DDT on the environment $[17,6]$. Hence malaria that would have been declining, continues to rise. This negative impact of current malaria control strategies means that search for other control technologies is inevitable. Such methods would be readily available, affordable, durable, safe and generally acceptable by the people.

It was against this background that a malaria control study was carried out in Oruku- a sub-urban community in Nkanu 
East Local Government Area, very near Enugu, in Enugu state, Nigeria, using Lambdacyhalothrin-treated curtain, mats and blankets as alternative strategy for malaria control. Above $44.29 \%$ reduction in malaria infection and other morbidity indicators such as hospital attendance, health seeking movement and school absenteeism was achieved at the end of the study $[9,3,4]$.

Prior to the village study, a pre-test/animal testing (safety testing) was done, using Guinea pigs to ascertain the effect of lambdacyhalothrin on physiological parameters of the Guinea pigs such as hemoglobin concentrations, rate of heart beat per minutes, respiration rate per minutes, erythrocyte sedimentation rate (ESR), Packed cell volume and temperature before using it in human habitation (Guinea pig has physiology similar to human).

Animal testing is the use of non-human animals in experimental research. Animals such as Armadillo, Bee, Cat, Dog, Equid, Ferret, Guinea pig, Hamster, Insect, Jellyfish, Kangaroo, Lagomorphs, Mouse, Nematode, Octopus, Pig, Quail, Rat, Sheep, Tamarin, Urchin, Vole, Watanabe rabbit, Xenopus, Yellow-beaked cleaner shrimp and Zebra fish have been used repeatedly through the history of biomedical research [1, 12]. In the 1880's Louis Pasteur convincingly demonstrated the germ theory of medicine by inducing anthrax in Sheep [7]. Ivan Pavlov famously used dogs to describe classical conditioning in 1890s [14]. [2] reported that insulin was first isolated from dogs in 1922 and the treatment of diabetes was revolutionized. According to [13] antibiotic treatment and vaccine for leprosy were developed using Armadillos in 1970 and then given to human [10]. In United States, the number of rats and mice used in research is estimated at 20 million a year [11].

Guinea pigs have contributed to 23 Nobel prizes for medicine with studies leading to the discovery of vitamin $\mathrm{C}$, the tuberculosis bacterium, adrenaline [12] as well as the development of vaccine for diphtheria and tuberculosis, replacement heart valves, blood transfusion, kidney dialysis, antibiotics, anticoagulants and asthma medicines [12]. Vitamin C was discovered using Guinea pig in 1907 and German scientist Kobert Koch used Guinea pigs to discover that Tuberculosis was caused by the mycobacterium tuberculosis in $1882[1,12)$. The sensitivity of the Guinea pig to this and other infections and the similarities of its immune defense system to that of humans have made it important in the study of infectious diseases. They have biological similarities to humans, beyond the simple fact that they are mammals which make them useful in many field of research [12].

Guinea pigs are domestic, social and docile rodent. [5] reported that Guinea pigs originated from South America. Today they are used in many areas of research including nutritional research, allergies/respiratory diseases, hearing and safety testing [12]. Presented below is a safety test carried out to evaluate the action of a pyrethroid insecticide Lambdacyhalothrin, on Guinea pigs prior to the community deployment of the insecticide in human habitation for control of malaria in villages outside Enugu.

\section{Materials and Methods}

From January 2003 to April 2003, an experimental study was carried out inside the Zoological garden, Department of Zoology, University of Nigeria, Nsukka. Five guinea pigs were used- their sexes were 3 males and 2 females. The Guinea pigs were collected from Ogbete Main Market, Enugu and then transported to the Zoological garden in a carton. The Guinea pigs were tagged A, B, C, D, E, but grouped in the ratio of 1:2:2 and kept in three different animal cages. Where animal ' $A$ ' was kept alone; the first two - B and $\mathrm{C}$ were together and the other two - D and E were also together. They were acclimatized and exposed to mosquitoes and other insects bite for 4 weeks (Jan $10^{\text {th }}$ to Feb. $11^{\text {th }}$ ). The ' $A$ ' animal which was alone served as a control while B, C, D and E served as experimental animals. Both the experimental animals and the control were located in the same ecosystem at least one meter away from one another. Four pieces of cloth (curtain) material $60 \mathrm{~cm} \times 40 \mathrm{~cm}$ treated with the experimental concentrations of lambdacyhalothrin, measured using standard method were hung inside the two cages that contain experimental animals (BCDE) on $12^{\text {th }}$ February 2003. The control animal was exposed to nothing.

\subsection{Data Collection}

Clinical parameters such as rate of heart beat per minutes, respiratory rate per minutes and body temperature (by inserting a clinical thermometer inside the anus) per minutes were measured daily. Also samples of blood were collected from the animals through the lateral wall of the tibia bone and sometimes from the angle of two digits, weekly with the help of veterinary personnel.

The experiment lasted for 15 weeks from January $10^{\text {th }}$ to April $30^{\text {th }}, 2003$. Within this period, the animals were fed with vegetations (grasses), Bambara nut and banana. The animal cages were cleared off of dirt (animal dung and food remains) every morning to avoid accumulation of rubbish. This is to create a healthy environment for the animals.

\subsection{Analysis of Data}

Data on hemoglobin concentration (HB), Packed Cell Volume (PCV) and Erythrocyte Sedimentation Rate (ESR) of animals $\mathrm{ABCDE}$ and data from rate of heart beat per minutes, respiratory rate per minutes and body temperature were analyzed using chi square, ratio (fscore), correlation coefficient ' $r$ ' and coefficient of determination $\left(r^{2}\right)$.

\section{Results}

Effects of the insecticide on (a) hemoglobin concentration (b) Packed cell volume (c) Erythrocyte sedimentation rate (d) rate of Heart beat (e) Respiratory rate (f) Temperature of animals B, C, D, and E are presented below. Guinea Pig labeled A was the control. 
Table 1. Effects of different concentrations of lambdacyhalothrin on hemoglobin concentration of Guinea pigs.

\begin{tabular}{|c|c|c|c|c|c|c|}
\hline \multirow{4}{*}{ Weeks } & \multirow{4}{*}{ Concentrations of lambdacyhalothrin (mg/l) } & \multicolumn{5}{|c|}{ Guinea pigs } \\
\hline & & \multicolumn{2}{|c|}{ (Control animal) } & \multicolumn{3}{|c|}{ (Experimental animals) } \\
\hline & & A & B & C & D & $\mathbf{E}$ \\
\hline & & \multicolumn{5}{|c|}{ Mean hemoglobin values } \\
\hline 1 & 0.001 & $13.9 \pm$ & $14.00 \pm$ & $13.9 \pm$ & $13.9 \pm$ & $13.9 \pm$ \\
\hline 2 & 0.005 & $13.9 \pm$ & $14.00 \pm$ & $13.9 \pm$ & $13.9 \pm$ & $13.9 \pm$ \\
\hline 3 & 0.010 & $13.9 \pm$ & $13.95 \pm$ & $13.9 \pm$ & $13.9 \pm$ & $13.9 \pm$ \\
\hline 4 & 0.015 & $13.9 \pm$ & $13.95 \pm$ & $13.9 \pm$ & $13.9 \pm$ & $13.9 \pm$ \\
\hline 5 & 0.020 & $13.9 \pm$ & $13.95 \pm$ & $13.9 \pm$ & $13.9 \pm$ & $13.9 \pm$ \\
\hline 6 & 0.025 & $13.9 \pm$ & $13.95 \pm$ & $13.9 \pm$ & $13.9 \pm$ & $13.9 \pm$ \\
\hline 7 & 0.030 & $13.9 \pm$ & $13.9 \pm$ & $13.85 \pm$ & $13.85 \pm$ & $13.9 \pm$ \\
\hline 8 & 0.035 & $13.9 \pm$ & $13.9 \pm$ & $13.8 \pm$ & $13.85 \pm$ & $13.9 \pm$ \\
\hline 9 & 0.040 & $13.9 \pm$ & $13.9 \pm$ & $13.8 \pm$ & $13.85 \pm$ & $13.85 \pm$ \\
\hline 10 & 0.045 & $13.9 \pm$ & $13.9 \pm$ & $13.8 \pm$ & $13.85 \pm$ & $13.85 \pm$ \\
\hline 11 & 0.050 & $13.9 \pm$ & $13.9 \pm$ & $13.8 \pm$ & $13.85 \pm$ & $13.85 \pm$ \\
\hline
\end{tabular}

$\left(\chi^{2}=20.73, \mathrm{df}=6, \mathrm{P}>0.01\right)$

Table 2. Effects of different concentrations of lambdacyhalothrin on packed cell volume of Guinea Pigs.

\begin{tabular}{|c|c|c|c|c|c|c|}
\hline \multirow{4}{*}{ Weeks } & \multirow{4}{*}{ Concentrations of lambdacyhalothrin (mg/l) } & \multicolumn{5}{|c|}{ Guinea pigs } \\
\hline & & \multicolumn{2}{|c|}{ (Control animal) } & \multicolumn{3}{|c|}{ (Experimental animals) } \\
\hline & & A & B & C & D & $\mathbf{E}$ \\
\hline & & \multicolumn{5}{|c|}{ Mean packed cell volume values } \\
\hline 1 & 0.001 & $40 \pm$ & $41 \pm$ & $40 \pm$ & $39 \pm$ & $41 \pm$ \\
\hline 2 & 0.005 & $40.5 \pm$ & $41 \pm$ & $40 \pm$ & $39 \pm$ & $41 \pm$ \\
\hline 3 & 0.010 & $40.5 \pm$ & $41 \pm$ & $40 \pm$ & $39 \pm$ & $41 \pm$ \\
\hline 4 & 0.015 & $40.5 \pm$ & $40.5 \pm$ & $40 \pm$ & $39 \pm$ & $41 \pm$ \\
\hline 5 & 0.020 & $40.5 \pm$ & $40.5 \pm$ & $40 \pm$ & $39 \pm$ & $41 \pm$ \\
\hline 6 & 0.025 & $40.5 \pm$ & $40.5 \pm$ & $40 \pm$ & $39 \pm$ & $40.5 \pm$ \\
\hline 7 & 0.030 & $40.5 \pm$ & $40 \pm$ & $39.5 \pm$ & $39.5 \pm$ & $40 \pm$ \\
\hline 8 & 0.035 & $40 \pm$ & $40 \pm$ & $39.5 \pm$ & $39.5 \pm$ & $40 \pm$ \\
\hline 9 & 0.040 & $40 \pm$ & $40 \pm$ & $39.5 \pm$ & $39.5 \pm$ & $40 \pm$ \\
\hline 10 & 0.045 & $40 \pm$ & $40 \pm$ & $39.5 \pm$ & $39.5 \pm$ & $40 \pm$ \\
\hline 11 & 0.050 & $40 \pm$ & $40 \pm$ & $39.5 \pm$ & $39 \pm$ & $40 \pm$ \\
\hline
\end{tabular}

$\left(\chi^{2}=52.86, \mathrm{df}=6, \mathrm{P}>0.001\right)$

Table 3. Effects of different concentrations of lambdacyhalothrin on Erythrocyte Sedimentation Rate (ESR) of Guinea pigs.

\begin{tabular}{|c|c|c|c|c|c|c|}
\hline \multirow{4}{*}{ Weeks } & \multirow{4}{*}{ Concentrations of lambdacyhalothrin (mg/l) } & \multicolumn{5}{|c|}{ Guinea pigs } \\
\hline & & \multicolumn{2}{|c|}{ (Control animal) } & \multicolumn{3}{|c|}{ (Experimental animals) } \\
\hline & & A & B & $\mathbf{C}$ & D & $\mathbf{E}$ \\
\hline & & \multicolumn{5}{|c|}{ Mean erythrocyte sedimentation rate Values } \\
\hline 1 & 0.001 & $2 \pm$ & $2 \pm$ & $2 \pm$ & $2 \pm$ & $2 \pm$ \\
\hline 2 & 0.005 & $2 \pm$ & $1.5 \pm$ & $1.5 \pm$ & $1.5 \pm$ & $2 \pm$ \\
\hline 3 & 0.010 & $1.5 \pm$ & $1.5 \pm$ & $1 \pm$ & $1.5 \pm$ & $2 \pm$ \\
\hline 4 & 0.015 & $1.5 \pm$ & $1.5 \pm$ & $1 \pm$ & $1.5 \pm$ & $1.5 \pm$ \\
\hline 5 & 0.020 & $1.5 \pm$ & $1 \pm$ & $1 \pm$ & $1 \pm$ & $1.5 \pm$ \\
\hline 6 & 0.025 & $1 \pm$ & $1 \pm$ & $1 \pm$ & $1 \pm$ & $1.5 \pm$ \\
\hline 7 & 0.030 & $1 \pm$ & $1 \pm$ & $1 \pm$ & $1 \pm$ & $1 \pm$ \\
\hline 8 & 0.035 & $1 \pm$ & $1 \pm$ & $1 \pm$ & $1 \pm$ & $1 \pm$ \\
\hline 9 & 0.040 & $1.5 \pm$ & $1 \pm$ & $1 \pm$ & $1 \pm$ & $1 \pm$ \\
\hline 10 & 0.045 & $1.5 \pm$ & $1 \pm$ & $1 \pm$ & $1 \pm$ & $1 \pm$ \\
\hline 11 & 0.050 & $1 \pm$ & $1 \pm$ & $1 \pm$ & $1 \pm$ & $1 \pm$ \\
\hline
\end{tabular}

Table 4. Effects of different concentrations of lambdacyhalothrin on rate of heart beat per minutes of Guinea pigs.

\begin{tabular}{|c|c|c|c|c|c|c|}
\hline \multirow{4}{*}{ Weeks } & \multirow{4}{*}{ Concentrations of lambdacyhalothrin $(\mathrm{mg} / \mathrm{l})$} & \multicolumn{5}{|c|}{ Guinea pigs } \\
\hline & & \multicolumn{2}{|c|}{ (Control animal) } & \multicolumn{3}{|c|}{ (Experimental animals) } \\
\hline & & $\mathbf{A}$ & B & $\mathrm{C}$ & D & $\mathbf{E}$ \\
\hline & & \multicolumn{5}{|c|}{ Mean heart rate values } \\
\hline 1 & 0.001 & $245 \pm$ & $245 \pm$ & $246 \pm$ & $245 \pm$ & $245 \pm$ \\
\hline 2 & 0.005 & $245 \pm$ & $245 \pm$ & $246 \pm$ & $245 \pm$ & $245 \pm$ \\
\hline 3 & 0.010 & $245 \pm$ & $245 \pm$ & $246 \pm$ & $245 \pm$ & $245 \pm$ \\
\hline 4 & 0.015 & $245 \pm$ & $245 \pm$ & $246 \pm$ & $245 \pm$ & $245 \pm$ \\
\hline
\end{tabular}




\begin{tabular}{|c|c|c|c|c|c|c|}
\hline \multirow{4}{*}{ Weeks } & \multirow{4}{*}{ Concentrations of lambdacyhalothrin (mg/l) } & \multicolumn{5}{|c|}{ Guinea pigs } \\
\hline & & \multicolumn{2}{|c|}{ (Control animal) } & \multicolumn{3}{|c|}{ (Experimental animals) } \\
\hline & & $\mathbf{A}$ & $\mathbf{B}$ & $\mathbf{C}$ & D & $\mathbf{E}$ \\
\hline & & \multicolumn{5}{|c|}{ Mean heart rate values } \\
\hline 5 & 0.020 & $245 \pm$ & $245 \pm$ & $246 \pm$ & $245 \pm$ & $245 \pm$ \\
\hline 6 & 0.025 & $245.5 \pm$ & $245 \pm$ & $246 \pm$ & $245 \pm$ & $245 \pm$ \\
\hline 7 & 0.030 & $245 \pm$ & $244.5 \pm$ & $246.5 \pm$ & $245 \pm$ & $245 \pm$ \\
\hline 8 & 0.035 & $245 \pm$ & $244.5 \pm$ & $246.5 \pm$ & $245 \pm$ & $245 \pm$ \\
\hline 9 & 0.040 & $245.5 \pm$ & $244.5 \pm$ & $246.5 \pm$ & $245 \pm$ & $245 \pm$ \\
\hline 10 & 0.045 & $245 \pm$ & $244.5 \pm$ & $246.5 \pm$ & $245.5 \pm$ & $245.5 \pm$ \\
\hline 11 & 0.050 & $245 \pm$ & $244.5 \pm$ & $246.5 \pm$ & $245.5 \pm$ & $245.5 \pm$ \\
\hline
\end{tabular}

$\left(\chi^{2}=412.72, \mathrm{df}=6, \mathrm{p}>0.01\right)$

Table 5. Effects of Different Concentrations of Lambdacyhalothrin on Respiratory rate per minute of Guinea pigs.

\begin{tabular}{|c|c|c|c|c|c|c|}
\hline \multirow{4}{*}{ Weeks } & \multirow{4}{*}{ Concentrations of lambdacyhalothrin (mg/l) } & \multicolumn{5}{|c|}{ Guinea pigs } \\
\hline & & \multicolumn{2}{|c|}{ (Control animal) } & \multicolumn{3}{|c|}{ (Experimental animals) } \\
\hline & & $\mathbf{A}$ & B & C & D & $\mathbf{E}$ \\
\hline & & \multicolumn{5}{|c|}{ Mean respiratory rate Values } \\
\hline 1 & 0.001 & $100 \pm$ & $100 \pm$ & $101 \pm$ & $101 \pm$ & $100 \pm$ \\
\hline 2 & 0.005 & $100 \pm$ & $100 \pm$ & $101 \pm$ & $101 \pm$ & $100 \pm$ \\
\hline 3 & 0.010 & $101 \pm$ & $100 \pm$ & $101 \pm$ & $101 \pm$ & $100 \pm$ \\
\hline 4 & 0.015 & $101 \pm$ & $100 \pm$ & $101 \pm$ & $101 \pm$ & $100 \pm$ \\
\hline 5 & 0.020 & $100.5 \pm$ & $100 \pm$ & $101 \pm$ & $101 \pm$ & $100 \pm$ \\
\hline 6 & 0.025 & $101 \pm$ & $100 \pm$ & $101 \pm$ & $101 \pm$ & $100 \pm$ \\
\hline 7 & 0.030 & $101 \pm$ & $100.5 \pm$ & $101 \pm$ & $101 \pm$ & $100 \pm$ \\
\hline 8 & 0.035 & $101 \pm$ & $100.5 \pm$ & $101 \pm$ & $101 \pm$ & $101 \pm$ \\
\hline 9 & 0.040 & $101 \pm$ & $100.5 \pm$ & $100.5 \pm$ & $100.5 \pm$ & $101 \pm$ \\
\hline 10 & 0.045 & $101 \pm$ & $100.5 \pm$ & $100.5 \pm$ & $100.5 \pm$ & $101 \pm$ \\
\hline 11 & 0.050 & $101 \pm$ & $101 \pm$ & $100.5 \pm$ & $100.5 \pm$ & $101 \pm$ \\
\hline
\end{tabular}

$\left(\chi^{2}=225.89, \mathrm{df}=6, \mathrm{p}>0.01\right)$

Table 6. Effects of Different Concentrations of Lambdacyhalothrin on temperature of Guinea pigs.

\begin{tabular}{|c|c|c|c|c|c|c|}
\hline \multirow{4}{*}{ Weeks } & \multirow{4}{*}{ Concentrations of lambdacyhalothrin (mg/l) } & \multicolumn{5}{|c|}{ Guinea pigs } \\
\hline & & \multicolumn{2}{|c|}{ (Control animal) } & \multicolumn{3}{|c|}{ (Experimental animals) } \\
\hline & & A & B & $\mathbf{C}$ & D & $\mathbf{E}$ \\
\hline & & \multicolumn{5}{|c|}{ Mean Temperature Values } \\
\hline 1 & 0.001 & $39.3 \pm$ & $39.3 \pm$ & $39.4 \pm$ & $39.4 \pm$ & $39.3 \pm$ \\
\hline 2 & 0.005 & $39.3 \pm$ & $39.3 \pm$ & $39.4 \pm$ & $39.4 \pm$ & $39.3 \pm$ \\
\hline 3 & 0.010 & $39.3 \pm$ & $39.3 \pm$ & $39.4 \pm$ & $39.4 \pm$ & $39.3 \pm$ \\
\hline 4 & 0.015 & $39.3 \pm$ & $39.3 \pm$ & $39.4 \pm$ & $39.4 \pm$ & $39.3 \pm$ \\
\hline 6 & 0.025 & $39.4 \pm$ & $39.3 \pm$ & $39.4 \pm$ & $39.4 \pm$ & $39.3 \pm$ \\
\hline 7 & 0.030 & $39.4 \pm$ & $39.3 \pm$ & $39.35 \pm$ & $39.4 \pm$ & $39.3 \pm$ \\
\hline 8 & 0.035 & $39.4 \pm$ & $39.25 \pm$ & $39.35 \pm$ & $39.35 \pm$ & $39.35 \pm$ \\
\hline 9 & 0.040 & $39.4 \pm$ & $39.25 \pm$ & $39.35 \pm$ & $39.35 \pm$ & $39.4 \pm$ \\
\hline 10 & 0.045 & $39.4 \pm$ & $39.25 \pm$ & $39.35 \pm$ & $39.35 \pm$ & $39.4 \pm$ \\
\hline 11 & 0.050 & $39.4 \pm$ & $39.25 \pm$ & $39.35 \pm$ & $39.35 \pm$ & $39.4 \pm$ \\
\hline
\end{tabular}

$-\chi^{2}=63.73, \mathrm{df}=6,>0.01$

\section{Discussion}

Results of these parameters for the experimental animals $\mathrm{B}, \mathrm{C}, \mathrm{D}$ and $\mathrm{E}$ were then compared with that of the control animal ' $A$ ' (Tables 1-6). The results show that lambdacyhalothrin at $0.001 \mathrm{mg} / \mathrm{l}$ and up to $0.050 \mathrm{mg} / \mathrm{l}$ concentrations had no adverse effect on hemoglobin concentration (HB), packed cell volume (PCV), erythrocyte sedimentation rates (ESR), rate of heart beat, respiratory rate and temperature of the test Guinea pigs respectively. When the readings were subjected to analysis using chi-square, the result showed that lambdacyhalothrin at these concentrations, had no significant effect on values of hemoglobin concentration $\left(\chi^{2}=20.73\right.$, df $\left.=6, P>0.01\right)$, values of packed cell volume $\left(\chi^{2}=52.86\right.$, df $\left.=6, \mathrm{P}>0.001\right)$, erythrocyte sedimentation rate, rate of heart beat $\left(\chi^{2}=412.72, \mathrm{df}=6, \mathrm{p}>\right.$ $0.01)$, respiratory rate $\left(\chi^{2}=225.89, \mathrm{df}=6, \mathrm{p}>0.01\right)$, and temperature values $\left(-\chi^{2}=63.73, \mathrm{df}=6,>0.01\right)$ of all the test Guinea pigs respectively. Further analysis with ratio (fscore) still showed that there were no significant differences between the 'ratio for the test animals B, C, D, E and their control ' $A$ '. The results were also tested with correlation coefficient $(r)$ and coefficient of determination $\left(\mathrm{r}^{2}\right)$, for hemoglobin concentration, $\mathrm{r}$ was found to be $\approx 0.9$ for the $\mathrm{B}$, $\mathrm{C}$, and $\mathrm{E}$ as well as for control animal A. That of $\mathrm{D}$ was 0.8 
$(\mathrm{df}=6, \mathrm{P}>0.01)$. The $\mathrm{r}^{2}$ were found to be 0.81 for $\mathrm{B}, \mathrm{C}, \mathrm{E}$ and their control A. It was 0.64 for $\mathrm{D}$, indicating that $81 \%$ changes in hemoglobin concentration of test animals B, C, and $\mathrm{E}$ were accounted for by the changes in concentration of lambdacyhalothrin. In D only $64 \%$ of such changes could be ascribed to changes in the concentration of the chemical.

Correlation coefficient ( $\mathrm{r}$ ) and coefficient of determination $\left(\mathrm{r}^{2}\right)$ analysis of packed cell volume showed $\mathrm{r}$ to be $\approx 0.9$ for both the test animals B, C, D, and E and the control animal A (df $=6, p>0.01$ ). The $r^{2}$ were found to be 0.81 for all the test animals as well as the control. This indicates that $81 \%$ changes in packed cell volume of all the test animals (B, C, D and $\mathrm{E}$ ) were accounted for by the changes in concentration of lambdacyhalothrin.

Equally Correlation coefficient ( $r$ ) and coefficient of determination $\left(\mathrm{r}^{2}\right)$ analysis of ESR values of the test animals and control, when compared, showed that $r$ was 0.9 for the test animals B, D and E as well as for the control A, that of C was $0.8(\mathrm{df}=6, \mathrm{p}>0.001)$. The $\mathrm{r}^{2}$ were found to be 0.81 for both the test animals B, D, E and the control A. It was 0.64 for animal $\mathrm{C}$, indicating that $81 \%$ changes in Erythrocyte sedimentation rate of test animals $\mathrm{B}, \mathrm{D}$, and $\mathrm{E}$ were accounted for by the changes in concentration of lambdacyhalothrin. In C, only $64 \%$ of such changes could be ascribed to changes in the concentration of the chemical.

Also when rate of heart beat of both the test animals and the control were further tested with correlation coefficient ' $r$ ' and coefficient of determination $r^{2}$ and compared, the $r$ was found to be 0.81 for test animals $\mathrm{B}$ and $\mathrm{C}$, it was 0.64 for $\mathrm{D}, \mathrm{E}$ as well as in control animal A. This indicates that $81 \%$ changes in rate of heart beat of $\mathrm{B}$ and $\mathrm{C}$ were accounted for by the changes in concentration of Lambdacyhalothrin while in D and E only $64 \%$ of such changes could be ascribed to changes in concentration of the chemical.

Likewise further analysis of the respiratory rate of all the test animals and their control using correlation coefficient ' $r$ ' and coefficient of determination $r^{2}$, the ' $r$ ' was found to be 0.9 for all the test animals B, C, D, E and their control A (df $=6, p>0.01) . r^{2}$ were found to be 0.81 for $\mathrm{B}, \mathrm{C}, \mathrm{D}$ and $\mathrm{E}$ as well as the control $\mathrm{A}$, indicating that $81 \%$ changes in respiratory rate of all the test animals were accounted for by the changes in the concentration of Lambdacyhalothrin.

Correlation coefficient (r) and coefficient of determination $\mathrm{r}^{2}$ analysis of temperature of both the test animals and control showed that $r$ was 0.9 for test animals C, D, E and their control A. It was 1 for animal $B(d f=6, p>0.01)$. The $r^{2}$ were found to be 0.81 for $\mathrm{C}, \mathrm{D}, \mathrm{E}$ as well as the control A. This also indicates that only $81 \%$ changes in the temperature of $\mathrm{C}, \mathrm{D}$ and $\mathrm{E}$ were accounted for by the changes in the concentration of lambdacyhalothrin while in B $100 \%$ of such changes was ascribed to changes in the concentration of the chemical.

\section{Conclusion}

From the result, it was found out that lambdacyhalothrin has neither acute nor residual effects on the guinea pigs, it was then concluded that it would not have any adverse effect on humans. Guinea pig has similar physiology to that of man. Based on this, it was decided that $0.001 \mathrm{mg} / \mathrm{l}$ and up to $0.050 \mathrm{mg} / \mathrm{l}$ concentration of the insecticide, if used in malaria and mosquito control studies in human habitations will not have any health hazard.

\section{Acknowledgements}

Heartfelt thanks to my supervisor, Prof Okafor, Fabian C. of Zoology and Environmental Biology Department, University of Nigeria, for his kind assistance.

\section{Note}

Suggested Possible New Topics for the paper:

Physiological Health Criteria for a Pyrethroid Insecticide: A Pre-test Study with Guinea Pigs

OR

Evaluation of a Pyrethroid Insecticide Against Physiological Parameters of Guinea Pigs: A Pre-Test Study at University of Nigeria Nsukka, Southeast Nigeria

\section{References}

[1] Costello, J. (2011). “The great zoo's who". Irish Independent. > http://www.independent. i.e. / lifestyle/thegreat-zoos-who. Html< Date accessed: April 9, 2012.

[2] Gorden, P. (1997). "Non- insulin dependent diabetes- the past, present and future". Annual Academic medical Sin gap, 26(3): 326-330.

[3] Greenwood, B. M. (1999). What can the resident of malaria endemic countries do to protect themselves against malaria. London School of Hygiene and Tropical Medicine,

[4] Greenwood, B. M. (1997). What's new in malaria control? Annual of Tropical Medicine and Parasitology, 91: 523 - 531.

[5] LVMA (2000). Biology of Guinea pig. Louisiana Veterinary Medical Association. 4p $>$ www.lvma.org/pig.html $<$ Date accessed: February 6, 2000.

[6] Malaria Consortium. (2016). Malaria consortium disease control, better health.

http://www.malariaconsortium.org/pages/109.htm.

[7] Mock, M. and Fouet, A. (2001). "Anthrax". Annual Review of Microbiology, 55: 647-67.

[8] Mutero, C. M., Mbogo, C., Mwangangi, J., Imbahale, S., Kibe, L., Orindi, B., Girma, M., Njui, A., Lwande, W., Affognon, H., Gichuki, C., and Mukabana1, W. R. (2015). An Assessment of Participatory Integrated Vector Management for Malaria Control in Kenya. Environmental Health Perspectives, volume 123( 11 ): 1145 -1151.

[9] Okoh, F. N., Odikamnoro, O. O., Uhuo, C. A., Okereke, C. N., Azi, S. O. and Ogidi, E. D. (2014). Epidemiology of malaria among children aged 1 to 15 years in South East Nigeria. Jounal of Public Health and Epidemiolgy. Academic Journals, volume 6(11): 390-397. 
[10] Scollard, D. M., Adams, L. B., Gillis, T., Krahenbuhl, J. L., Truman, R. W., and Williams, D. L. (2006). "The continuing challenges of leprosy". Clinical Microbiology Review, 19(2): 338-81 http://www.pubmedcentral.gov/articlerender.fcgi.

[11] Trull, F. L, Rich, B. A. (1999). More Regulation of Rodents Science. PubMed 284 (5419): 1463.

[12] UAR. (2012). Guinea pig in medical research, $A-Z$ of Different Animals Used. Understanding Animals Research. $>$ www.understandinganimalresearch.org.uk.html $<\mathrm{D}$ ate accessed: April 9, 2012.

[13] Walgate, R. (1981). "Armadillos fish leprosy". Nature, 291(5816): 527 http://www.nebi.nih.gov/pubmed/7242665.

[14] Windholz, G. (1987). "Pavlov as a psychologist. A reappraisal" Pavlov Journal of Biological Science, 22(3): 103112. http://www.ncbi.nlm.nih.gov/pubmed.
[15] World Health Organization.(2014). World malaria report, 2014, http://www.who.int/malaria/WMR014.

[16] World Health Organization.(2013). World malaria report, 2013, http://www.who.int/malaria/WMR0143.

[17] World Health Organization. (2006). Global malaria programme: Use of indoor residual spraying for scaling up global malaria control and elimination. http://apps.who.int/iris/bitstream/10665/69386/1/WHO HTM _MAL_2006.1112_eng.pdf.

[18] World Health Organization. (2005). World health report, 2005. Make every mother and child count. http://www.who.int/whr/2005/en/. 